\title{
MICHEL FOUCAULT E OS ESTUDOS LINGUÍSTICOS: REFLEXÕES SOBRE AS NOÇÕES DE LÍNGUA E ESTRUTURA NA ANÁLISE ARQUEOLÓGICA
}

\author{
Lucas Martins Gama Khalil
}

\begin{abstract}
RESUMO
Este artigo apresenta uma reflexão sobre a inserção da obra de Michel Foucault nos estudos linguísticos. Para isso, focalizamos o desenvolvimento das noçôes de língua e estrutura - tão importantes nessa área de estudos - em alguns textos do autor, objetivando sublinhar convergências e deslocamentos efetuados.
\end{abstract}

PALAVRAS-CHAVE: Foucault; língua; análise arqueológica.

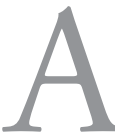

obra do filósofo Michel Foucault abrange, ao abordar temas como sujeito, discurso e poder, diversos campos de conhecimento. Em vista da recorrente assunção de conceitos foucaultianos no interior da Análise do Discurso, muitos pesquisadores da Linguística fundamentam seus trabalhos a partir de obras do autor, como A arqueologia do saber (1969) e As palavras e as coisas (1966). A inserção de Michel Foucault em pesquisas situadas no amplo campo da Linguística, no entanto, demanda ao pesquisador atenção a aspectos basilares, como as noçôes de língua e estrutura. Para o entendimento dessas noçóes, por exemplo, precisa-se considerar toda uma rede de conceitos que, de certo modo, foram adquirindo legitimidade a partir de determinados arcabouços teóricos no interior da própria Linguística. As variadas referências à Linguística - inclusive ao Gerativismo - em textos do filósofo constituem, dessa forma, um terreno fértil para observarmos deslocamentos e/ou alianças teóricas. 
Levando-se em consideração que aspectos teóricos e metodológicos sobre o enunciado foucaultiano constituem base para diversos trabalhos em Linguística, cabe perguntarmos: a partir de que aspectos a análise enunciativa presente em A Arqueologia do Saber permite um estudo sobre a língua? Embora Foucault admita explicitamente que seu objeto de investigação não é a língua e que o enunciado não se localiza no mesmo nível desta, supomos que, a partir de um acurado trabalho do pesquisador, a proposta da análise enunciativa que encontramos em A Arqueologia do Saber pode trazer contribuiçóes para o estudo da língua. O próprio autor afirma que a materialidade linguística não é dada ao enunciado como mero suplemento, mas constitutiva de seus possíveis sentidos.

Devido à grande extensão e à heterogeneidade da obra de Foucault, que suscita, por exemplo, expressóes como "fase arqueológica" e "fase genealógica", salientamos que os textos do filósofo escolhidos para o desenvolvimento da temática proposta foram produzidos entre 1964 e 1972, período de intensa ressonância de $A$ arqueologia do saber e As palavras e as coisas.

Ferdinand de Saussure é considerado o fundador da Linguística moderna. As diversas correntes que sucederam a sua obra Curso de Linguistica Geral (1916) doravante CLG, estabelecem relações específicas de divergência, deslocamento ou concordância com o conceito de língua apresentado por Saussure. Desse modo, os trabalhos inseridos na área da Linguística sustentam variadas noçóes de língua que, quando atravessadas pela noção de sistema desenvolvida pelo CLG, encaram-na de acordo com os parâmetros impostos pela perspectiva teórica adotada. Os trabalhos em Linguística que lançam mão de um arcabouço teórico baseado em conceitos foucaultianos, sendo assim, não deixam de fazer face às redes conceituais que atingiram certo grau de consistência na área.

As referências a Saussure na obra de Michel Foucault concernem, em sua maioria, à denominação constantemente atribuída ao linguista suíço: "estruturalista”. Foucault propóe em alguns textos, como veremos adiante, conjuntar uma dada noção de estruturalismo e um determinado olhar para a história. Entretanto, se Foucault faz referência a esse Saussure "estruturalista", o que entender por essa denominação? O termo "estrutura" foi recorrentemente interpretado, na recepção da obra de Saussure, como um mecanismo totalmente fechado, que, entre outras coisas, excluiria a "história" e o "sujeito". Por isso, 
faz-se a ressalva de que muitas das referências à "estrutura" na obra foucaultiana respondem mais a essa interpretação - que consideramos reducionista em relação aos estudos de Saussure - do que propriamente ao desenvolvimento da noção de sistema no CLG.

Ducrot alerta-nos que "se se entender por estrutura toda organização regular, a pesquisa de estruturas linguísticas é tão velha quanto o estudo das línguas" (DUCROT, 1968, p. 24). Considerando que esse sentido lato da palavra "estrutura" não corresponde ao corte efetuado na chamada fundação da Linguística moderna, cabe perguntarmos o que renova a noção de estrutura no CLG: "O Estruturalismo do século XX não terá, portanto, de introduzir, em Linguística, a noção de estrutura, que nela se encontra desde o começo. Sua originalidade será antes estabelecer, pela reflexão acerca das línguas, uma nova significação para essa palavra" (DUCROT, 1968, p. 24). Sendo a própria palavra "estrutura" pouco utilizada no decorrer do CLG, a explicação dessa noção geralmente perpassa o caráter da língua como sistema. Saussure afirma que "a língua tem o caráter de um sistema baseado completamente na oposição de suas unidades concretas" (SAUSSURE, 1972, p. 124). Consequentemente, não bastar haver um conjunto de signos para que haja a estrutura, conceito que implicaria a interdependência das unidades concretas. Essa interpretação da noção de estrutura perdura, legitimando-se em outros trabalhos teóricos que receberam a insígnia de "estruturalistas". François Wahl - em prefácio do livro Estruturalismo e Linguistica - afirma, por exemplo, que "Claude Lévi-Strauss dava por objeto às ciências estruturais aquilo que 'oferece um caráter de sistema', isto é, qualquer conjunto de que um elemento não pode ser modificado sem acarretar uma modificação de todos os outros" (DUCROT, 1968, p. 15). A estrutura, nesse sentido, acarretaria um conjunto de relaçóes de interdependência entre elementos, cujos valores definir-se-iam pelas oposiçóes, pelo fato de um elemento ser o que o outro não é, combinar-se com uma unidade e não com outras, ser passível de seleção em determinados lugares da cadeia linguística, entre outros aspectos. O olhar para as relaçóes entre as unidades concretas do sistema implica, no CLG, um recorte predominantemente sincrônico, isto é, visualiza-se um estado de língua, que "se define pela ausência de transformaçóes" (SAUSSURE, 1972, p. 118), apenas apreensível a partir de uma simplificação convencional dos dados. É imprescindível lembrar também que há uma grande parte do CLG dedicada ao estudo da Linguística 
diacrônica; porém, são as reflexóes acerca da sincronia que adquiriram maior ressonância no interior dos estudos linguísticos.

Embora compreendamos que diacronia e historicidade não são conceitos equivalentes, existe certa tendência, com relação à recepção do Estruturalismo, a antagonizar sistema e história. Muitas das críticas feitas a Saussure, e ao Estruturalismo de modo geral, giram em torno de um "esquecimento da história” ou de um "apagamento do sujeito". Nota-se, em interpretaçóes desse tipo, a noção de estrutura como um mecanismo fechado e completamente autossubsistente.

Entretanto, há diversos modos de conceber essa "estrutura" e lidar com ela. Michel Foucault, no texto Retornar à história, aponta, como já adiantávamos, uma conjunção possível entre a sistematicidade e a historicidade: "O estruturalismo, definindo as transformaçóes, a história, descrevendo os tipos de acontecimentos e os tipos de duração diferentes, torna possíveis simultaneamente o aparecimento das descontinuidades na história e o aparecimento de transformaçôes regradas e coerentes" (FOUCAULT, 2000a, p. 295). A questão das descontinuidades, recorrente na obra foucaultiana, não coadunaria com a ideia de estruturas como mecanismos fechados, presente em algumas interpretações provenientes da recepção do Estruturalismo. Por outro lado, o autor não parece negar a existência de estruturas, entendidas a partir de funcionamentos regrados e coerentes. Esse apontar para uma abertura no sistema linguístico, brecha que permite o atravessamento de aspectos discursivos, direciona o olhar do pesquisador que trabalha com Foucault para as emergências singulares dos enunciados, focalizando o aspecto do sentido.

Julgamos necessário, a fim de apresentarmos como a noção de língua é tratada na obra foucaultiana, traçar um percurso de textos do autor que são perpassados por tal temática, observando o modo como se efetuam os deslocamentos em relação a algumas correntes linguísticas em evidência no século XX.

Em conferência intitulada Linguagem e Literatura, de 1964 - anterior, portanto, às obras As palavras e as coisas e $A$ arqueologia do saber-, Foucault já adiantava algumas questóes que corroboram a ideia de que (dada noção de) estruturalismo e história podem admitir certas compatibilidades: "A linguagem é tanto o fato das palavras acumuladas na história quanto o próprio sistema da língua” (FOUCAULT, 2000b, p. 140). Quando Foucault faz referência ao 
"sistema da língua", consideramos que havia certa leitura do CLG, tendo em vista a sua posterioridade em relação à obra de Saussure. No excerto, a questão dos movimentos no interior do próprio sistema linguístico, propiciados pela ação da história, é que parece fundamentar as especificidades da proposta apresentada por Foucault. Em outra passagem da mesma conferência, Foucault afirma: "O que permite a um signo ser signo não é o tempo, mas o espaço” (FOUCAULT, 2000b, p. 168). O olhar para a história, em estudos sobre a linguagem, não equivale, nesse sentido, a exemplificar mudanças linguísticas com relação a épocas diferentes (tal como vosmicê - você); por outro lado, há aspectos da historicidade que determinam, por exemplo, a produção de um enunciado e dos sentidos dele decorrentes. Visualiza-se tal processo, como se percebe na citação, com relação à dada disposição dos signos em um panorama que mais se aproxima de uma noção de sincronia do que de estudos propriamente diacrônicos. Quando se fala em espaço, suscita-se não apenas o valor de um signo em relação a outro, em uma perspectiva saussureana, mas também os lugares que produzem dizeres "autorizados", os efeitos de sentido dos signos no interior de uma formação discursiva e não de outra.

Dois anos mais tarde, a problemática da linguagem (e de seu estudo) é tratada mais explicitamente no livro As palavras e as coisas. Nele, Foucault se propóe a realizar um trabalho de cunho epistemológico e, para esse fim, elege três grandes áreas do conhecimento: as ciências da vida, as ciências da linguagem e as ciências econômicas. É interesse de Foucault demonstrar como tais campos do conhecimento constituem seus funcionamentos com relação a determinados saberes sobre o homem, pois "as ciências humanas, com efeito, endereçam-se ao homem na medida em que ele vive, em que fala, em que produz" (FOUCAULT, 1999, p. 485). Para chegar a uma concepção de linguagem coerente com a noção de ciência humana, Foucault traça um panorama que expóe diversas teorizações, passando, por exemplo, pela noção de linguagem como representação direta e natural do mundo (por essa "semelhança”, as palavras sussurrariam seus nomes aos objetos e às pessoas). Expóe-se também o modelo de racionalidade atribuído ao que Foucault denomina Idade Clássica; são constantes as referências, por exemplo, à Gramática de Port-Royal e à ideia de gramática geral que é sustentada. No decorrer do que Foucault chama de Idade Moderna, os limites da representação começam a ser questionados, abrindo espaços para a visualização de um dado homem e 
de uma dada história (ainda distante da historicidade proposta pelos estudos discursivos, por exemplo); no campo dos saberes linguísticos, evidenciam-se, segundo Foucault, os estudos da Filologia, fundamentalmente diacrônicos.

Foucault, entretanto, nos apontamentos finais dessa obra, evoca a metáfora de Nietzsche "morte de Deus" para afirmar a "morte do homem", pondo em cena a figura de um sujeito esfacelado, que não gerencia a linguagem a partir de um controle pleno do dizer e dos sentidos. As ciências humanas estudam, sim, o homem, mas é essa concepção de homem que direcionará as reflexões teóricas. $\mathrm{Na}$ medida em que não se focaliza o indivíduo de carne e osso, mas as posições-sujeito construídas nos enunciados, torna-se possível estudar os discursos, que, para Foucault, são inseparáveis da linguagem: "A linguagem é toda ela discurso, em virtude desse singular poder de uma palavra que passa por sobre o sistema de signos em direção ao ser daquilo que é significado" (FOUCAULT, 1999, p. 132). Não deixando de atestar a existência de um "sistema de signos", o trecho acima ressalta o interesse principal de Foucault com relação aos estudos da linguagem: o que permite determinada significação e não outra.

O filósofo, no decorrer do percurso que acabamos de descrever de forma bastante abreviada, marca explicitamente o lugar da língua em sua perspectiva teórica:

Embora o homem seja, no mundo, o único ser que fala, não constitui ciência humana conhecer as mutaçóes fonéticas, o parentesco das línguas, a lei dos desvios semânticos; em contrapartida, poder-se-á falar de ciência humana desde que se busque definir a maneira como os indivíduos ou grupos representam as palavras, utilizam sua forma e seu sentido, compóem discursos reais, mostram e escondem neles o que pensam, dizem, talvez à sua revelia, mais ou menos do que pretendem, deixam desses pensamentos, em todo o caso, uma massa de traços verbais que é preciso decifrar e restituir, tanto quanto possível, à sua vivacidade representada. (FOUCAULT, 1999, p. 488).

Nesse excerto, Michel Foucault destaca a "vivacidade" dos traços verbais, o modo como eles constituem efetivamente os discursos. Isso, para o teórico, 
aproxima-se de uma prática que pode ser denominada "ciência humana". Outros tipos de interesse, como as citadas mutaçóes fonéticas, aparecem como linhas de estudo relativas à língua, mas que se afastam da "vivacidade representada" ou do próprio homem. Longe de constituir uma completa subestimação de outros estudos linguísticos, enxergamos esse tipo de colocação como um balizamento necessário, que evidencia os objetivos e os objetos (mesmo sendo "língua", qual "língua"?) de determinada perspectiva teórica.

A recepção da obra As palavras e as coisas gerou diversos tipos de questionamentos e interpretações, como a de que Foucault estaria supostamente apresentando grandes pensamentos de época, o que não coadunaria com sua perspectiva de história descontínua. Assim, em muitos de seus textos posteriores, tal como Resposta a uma questão (1968), Foucault realiza exercícios de explicação e de delimitação dos seus objetos de estudo. Nesse panorama, ele esclarece o que realmente lhe interessa nos estudos da língua e da linguagem:

O que analiso em um discurso não é o sistema de sua língua, nem, de uma maneira geral, as regras formais de sua construção; pois não me preocupo em saber o que o torna legítimo, ou the dá sua inteligibilidade e lhe permite servir à comunicação. A questão que coloco é aquela, não dos códigos, mas dos acontecimentos: a lei da existência dos enunciados, o que os torna possíveis - eles e algum outro em seu lugar; as condições de sua emergência singular; sua correlação com outros acontecimentos anteriores ou simultâneos, discursivos ou não. (FOUCAULT, 2010, p. 9)

Observa-se que Foucault enumera diversas possibilidades de estudo partindo de produçôes linguísticas. Pode-se estudar, por exemplo, as construçóes sintáticas "inteligíveis" em uma língua, as regras de combinação das palavras etc. O foco do teórico, entretanto, está nas condiçóes de possibilidade que permitem o aparecimento dos enunciados, em acontecimentos discursivos singulares - não factuais, mas produzidos no e pelo discurso. Esse olhar para a língua proporciona a aproximação entre a perspectiva foucaultiana e estudos linguísticos associados à enunciação e ao discurso. 
Em Sobre as maneiras de escrever a história, Foucault é categórico ao discorrer sobre o que seria seu objeto de estudo: "Meu objeto não é a linguagem, mas o arquivo, ou seja, a existência acumulada dos discursos" (FOUCAULT, 2000c, p. 72). Todavia, as noçôes de língua, linguagem e discurso parecem estar imbricadas nos estudos foucaultianos: A língua é um conjunto de estruturas, mas os discursos são unidades de funcionamento, e a análise da linguagem em sua totalidade não pode deixar de fazer face a essa exigência fundamental [...] não somente da língua que permite dizer, mas dos discursos que foram ditos" (FOUCAULT, 2000c, p. 72).

Concentrando-nos na denominação "estrutura", tal perspectiva não se direciona para a negação de um funcionamento interno da língua, mas para um alargamento de suas modalidades de regulação. Foucault interessa-se pelo que a língua permite produzir em sua utilização, isto é, os discursos, que determinarão, inclusive, a seleção e a combinação dos próprios signos. Para ele, "a linguística permitiu, enfim, analisar não somente a linguagem, mas os discursos, isto é, ela permitiu estudar o que se pode fazer com a linguagem" (FOUCAULT, 2000d, p. 166).

Desconsiderar integralmente o caráter da língua como sistema parece constituir um problema, tendo em vista os avanços que a fundamentação dessa característica proporcionou aos estudos linguísticos. Por outro lado, os estudos de Michel Foucault apontam para um tratamento específico dos fenômenos linguísticos, dando uma maior ênfase a elementos como o que ele denomina "prática humana", no trecho abaixo:

Se não houvesse o sujeito falante para retomar a cada instante a língua, habitá-la no seu interior, contorná-la, deformá-la, utilizá-la, se não houvesse esse elemento da atividade humana, se não houvesse a palavra no próprio cerne do sistema da língua, como a língua poderia evoluir? Ora, a partir do momento em que se deixa de lado a prática humana para se considerar apenas a estrutura e as regras de coerção, é evidente que se falha novamente em relação à história. (FOUCAULT, 2000a, p. 285)

No excerto acima, retirado do texto Retornar à história, Foucault aponta explicitamente para aquilo que considera uma falha: retirar da língua o seu 
caráter de acontecimento, de atividade. Quando o autor fala da "palavra no próprio cerne do sistema da língua", essa "palavra" pode ser entendida como aquilo que efetivamente se produz em enunciados. Por conseguinte, a "palavra” só movimenta a língua a partir da prática de sujeitos. Nota-se também a relação de não transparência entre sujeitos e sentidos, afinal, o sujeito não é concebido como um "habitante" da língua, meramente um ser decodificador; ele "deforma", "contorna” a língua, nas palavras do autor. Vale salientar, entretanto, que a crítica à desconsideração da história e do sujeito não parece estar direcionada propriamente a Saussure ou ao CLG, mas a determinada interpretação do Estruturalismo; tal interpretação enxergaria as estruturas como sistemas completamente herméticos, ideia que consideramos reducionista frente ao campo de reflexóes aberto pelos teóricos ditos "estruturalistas".

Entre os livros de Foucault, um dos mais requisitados com relação a temáticas pertinentes no âmbito dos estudos linguísticos é $A$ arqueologia do saber. Nele, encontramos uma consistente fundamentação teórica e metodológica para o exercício de uma análise dita "arqueológica”, metáfora que pode ser entendida no sentido de uma investigação da historicidade dos enunciados, uma "escavação" - utilizando outra metáfora. Embora já tenhamos mostrado que Foucault não concebe a língua como seu objeto de estudo, o conceito de enunciado, desenvolvido no decorrer dessa obra, oferece ferramentas ao pesquisador que trabalha com a língua em uma perspectiva foucaultiana. No capítulo Definir o enunciado, Foucault explicita a diferença entre o nível enunciativo e o nível propriamente linguístico:

Se não houvesse enunciados, a língua não existiria; mas nenhum enunciado é indispensável à existência da língua (e podemos sempre supor, em lugar de qualquer enunciado, um outro enunciado que, nem por isso, modificaria a língua). A língua só existe a título de sistema de construção para enunciados possíveis; mas, por outro lado, ela só existe a título de descrição (mais ou menos exaustiva) obtida a partir de um conjunto de enunciados reais. Língua e enunciado não estão no mesmo nível de existência; e não podemos dizer que há enunciados como dizemos que há línguas. (FOUCAULT, 2000e, p. 96-7) 
No panorama traçado, a língua tem sua existência subordinada à produção enunciativa. Se não circulassem discursos, a utilização de elementos linguísticos esvaziar-se-ia. Leitores de Foucault, como Jean-Jacques Courtine (2009), falam em "nível terminal" ao se referir ao nível linguístico, sendo que o nível enunciativo, por sua vez, exerce um papel de regulador do que se efetivamente produz com os elementos da língua (por que se produz x e não y em seu lugar?). O nível enunciativo seria aquele que comporta, dessa forma, regularidades pré-terminais, que podemos compreender mais eficientemente na delimitação do conceito de enunciado exposta a seguir.

Antes de apresentar uma conceituação mais direta de "enunciado", Foucault trata de distingui-lo de outras categorias recorrentes na análise de elementos linguísticos. Para tal empreendimento, Foucault faz uma comparação entre a sua noção de enunciado e outras três unidades recorrentes em estudos sobre linguagem: a proposição, a frase e o ato de fala, todas provenientes de domínios teóricos distintos. $\mathrm{O}$ enunciado difere-se da proposição, termo que Foucault relaciona à Lógica, pelo fato de não obedecer aos mesmos critérios de identificação. Enquanto sequências linguísticas aparentemente parafrásticas, por exemplo, poderiam ser encaradas como variantes de uma mesma verdade proposicional, baseadas em um referente em comum, o mesmo não se diria do enunciado: dependendo do campo de correlaçóes que é suscitado, determina-se a produção de alguns sentidos e não outros. Se, complementarmente, relacionarmos a própria noção de verdade da Lógica e a noção de verdade na obra de Foucault - vontades de verdade que são geridas no interior das formações discursivas -, a equivalência entre proposição e enunciado já se tornaria impraticável. $\mathrm{O}$ enunciado também não equivale à frase, a uma estrutura gramatical isolável a partir de determinado parâmetro. Podemos citar diversas materialidades que escapam ao padrão frasal, por exemplo, tabelas, gráficos, árvores genealógicas etc., materialidades que, se relacionadas com singulares práticas discursivas, constituem também enunciados. Por fim, o conceito que mais se aproximaria de enunciado, para Foucault, é o ato ilocutório, noção por ele atribuída aos analistas ingleses (referência aos estudos de Austin concernentes à teoria dos atos de fala). Ambos os conceitos, ato ilocutório e enunciado, apresentam apontamentos relativos à exterioridade das materialidades linguísticas; porém, a diferença principal é que o ato de fala refere-se apenas - na visão de Foucault - ao "que se produziu pelo próprio fato de ter sido 
enunciado" (FOUCAULT, 2000e, p. 94), enquanto o enunciado póe em cena o que é preexistente ao momento da enunciação, uma anterioridade histórica, e, inclusive, o que se pôde/pode produzir depois do próprio enunciado, um domínio de antecipação.

O enunciado, como elemento básico do discurso, encontra-se, assim como o discurso, na mútua relação de determinação entre língua e exterioridade. As regras de formação que são postas em prática pelas materialidades linguísticas localizam-se, portanto, no nível enunciativo, lugar teórico a partir do qual se tornam possíveis os estudos sobre as discursividades. O enunciado, não equivalendo, portanto, à proposição, à frase e ao ato de fala, é definido desta forma por Foucault:

O enunciado não é, pois, uma estrutura (isto é, um conjunto de relaçóes entre elementos variáveis, autorizando assim um número talvez infinito de modelos concretos); é uma função de existência que pertence, exclusivamente, aos signos, e a partir da qual se pode decidir, em seguida, pela análise ou pela intuição, se eles "fazem sentido" ou não, segundo que regra se sucedem ou se justapóem, de que são signos, e que espécie de ato se encontra realizado por sua formulação. (FOUCAULT, 2000e, p. 98-99)

Mesmo sendo afirmado, em alguns momentos da Arqueologia, como a "unidade elementar do discurso" (FOUCAULT, 2000e, p. 91), o enunciado não "é em si mesmo uma unidade, mas sim uma função que cruza um domínio de estruturas e de unidades possíveis e que faz com que apareçam, com conteúdos concretos, no tempo e no espaço" (FOUCAULT, 2000e, p. 99). Quando recortamos sequências linguísticas para análise, dentro dessa perspectiva, obviamente se lida com suas condiçóes materiais de emergência; entretanto, o que permite chamarmos uma frase de enunciado, por exemplo, é o singular tratamento conferido pelo pesquisador, que descreverá a inscrição desse acontecimento de linguagem em uma rede enunciativa, constituída por práticas sócio-históricas. A função enunciativa permite que se reflita, sobretudo, sobre o aparecimento de determinado enunciado e não outro em seu lugar; é nesse quadro, a propósito, que os modos de organização das materia- 
lidades (domínio de estruturas e unidades possíveis, como a frase, inclusive) adquirem fundamental importância na produção de sentidos. Salienta-se, a fim de que não se banalize o termo "estrutura", que "as estruturas" citadas nesse trecho apontam mais para a existência de uma série de unidades formalizáveis - como a frase - do que propriamente para o caráter sistemático da língua, que implicaria uma discussão mais focalizada.

Se o enunciado é uma função, em que consiste a chamada função enunciativa? Ela pode ser compreendida como um mecanismo que rege as relaçôes entre os discursos e o aparecimento de materialidades. Quando não se arrola tal discussão, acreditamos que dificilmente está se falando do enunciado foucaultiano. A concepção de enunciado, nessa perspectiva, é delineada a partir de quatro características principais. A primeira característica diz respeito ao correlato de um enunciado, que, para Foucault, não é um referente imediato no "real", nem um contexto definido em uma perspectiva estritamente sociológica. Concebe-se o enunciado foucaultiano em um campo de correlações, isto é, "um conjunto de domínios em que tais objetos podem aparecer e em que tais relaçóes podem ser assinaladas" (FOUCAULT, 2000e, p. 104). Uma mesma sequência linguística, desse modo, não constituiria um mesmo enunciado se produzida em um guia de viagens ou no interior de uma obra literária, por exemplo. As estratégias de atestação de verdades, as leis de possibilidade acerca daquilo que é dito, o tratamento dos objetos, entre outros fatores, são determinados pela inserção dos enunciados em uma rede. A segunda característica afirma uma relação peculiar entre enunciado e sujeito. Não se fala em sujeito como indivíduo de carne e osso, mas como uma posição, um lugar marcado sócio-historicamente, que pode ser ocupado por indivíduos. Nesse sentido, a constituição desse sujeito da Arqueologia admite várias vozes e o jogo de contradição entre elas (não entendemos contradição apenas como contraditoriedade, mas também como aliança, delimitação mútua). A terceira característica do enunciado nos remete a um axioma de base da teoria arqueológica foucaultiana: "Um enunciado tem sempre margens povoadas de outros enunciados" (FOUCAULT, 2000e, p. 112). Isso significa dizer que a produção de um enunciado singular reatualiza outros enunciados, não apenas se associando a eles, mas deslocando suas relações. A última característica do enunciado da Arqueologia consiste no pressuposto de que o enunciado deve ter uma existência material: "O enunciado tem necessidade dessa materialidade; mas ela não lhe é dada em suplemento, uma vez estabelecida 
todas as suas determinações: em parte, ela o constitui" (FOUCAULT, 2000e, p. 115). Ao analista do discurso, ou ao "linguista foucaultiano", não se coloca como princípio desvendar a verdade por trás das palavras, mas descrever o funcionamento das possibilidades relativas à produção de efeitos de sentido. Sendo assim, as palavras não são véus descartáveis; importa, e muito, o modo como se diz em relação a como se deixou de dizer. As materialidades verbais e não verbais são constitutivas do enunciado e os efeitos de sentido não podem deixar de supor a repetibilidade dessas materialidades. Para Foucault, o regime de materialidade repetível caracteriza o enunciado. Isso implica sustentar que "a enunciação é um acontecimento que não se repete” (FOUCAULT, 2000e, p. 116), enquanto a materialidade do enunciado pode se repetir e é justamente a partir dessa possibilidade que um mesmo signo, por exemplo, recebe determinaçóes semelhantes ou divergentes a depender das formaçóes discursivas envolvidas e das condiçóes de produção dos acontecimentos discursivos. Foucault explica que:

O enunciado tem a particularidade de poder ser repetido: mas sempre em condições estritas. Essa materialidade repetível que caracteriza a função enunciativa faz aparecer o enunciado como um objeto específico e paradoxal, mas também como um objeto entre os que os homens produzem, manipulam, utilizam, transformam, trocam, combinam, decompóem e recompóem, eventualmente, destroem. (FOUCAULT, 2000e, p. 121)

É principalmente sobre essa última característica, a necessidade material dos enunciados, que se fundam as possibilidades de estudos baseados na análise arqueológica de Foucault no interior da Linguística. Destacamos a afirmação: "ela (a materialidade) não lhe é dada (ao enunciado) em suplemento". Nesse sentido, a língua não é algo que, ao ser base de processos discursivos, esvazia-se de quaisquer vestígios de funcionamento peculiar. As materialidades, mesmo sofrendo deslocamentos no âmbito do sentido, não estão alheias às características do funcionamento da língua. $\mathrm{O}$ modo como se enuncia, intimamente ligado à materialidade, é constitutivo das estratégias discursivas, que, transcendendo à materialidade bruta, suscitam questóes como o lugar de onde se enuncia, para quem se enuncia (enunciatário), que campo de correlações é gerado, entre outras. Cabe perguntarmos, portanto: 
Qual é, pois, essa materialidade própria do enunciado e que autoriza certos tipos de repetição? Como se pode falar do mesmo enunciado onde há várias enunciações distintas - enquanto devemos falar de vários enunciados onde podemos reconhecer formas, estruturas, regras de construção, alvos idênticos? Qual é, pois, esse regime de materialidade repetivel que caracteriza o enunciado? (FOUCAULT, 2000e, p. 117)

Voltando-nos à conjunção entre estruturalismo e história, proposta por Foucault, o olhar para o sistema da língua tende a ser inevitável, pois as operaçooes de combinação e seleção de elementos linguísticos, por exemplo, são algumas das constantes preocupaçóes desse tipo de abordagem. Sendo assim, o deslocamento teórico dar-se-ia por meio de um objetivo peculiar, explicitamente apresentado por Foucault um ano antes da publicação de $A$ arqueologia do saber: "A questão própria da análise do discurso poderia ser formulada da seguinte maneira: qual é essa irregular existência que emerge no que se diz -e em nenhum outro lugar?" (FOUCAULT, 2000f, p. 93). Trabalhando-se com materialidades efetivamente produzidas, seria tarefa específica desse "analista do discurso" apreender as singularidades de acontecimentos discursivos; para isso, precisariam ser analisadas, acuradamente, as modalidades de repetibilidade da materialidade em questão, frente a específicas condiçôes de produção.

Apresentadas algumas das possíveis relaçóes entre o enunciado da Arqueologia e estudos sobre a língua, podemos trazer à tona, por fim, um texto no qual Foucault posiciona-se com relaçáo ao Estruturalismo e a certas correntes da Linguística, intitulado Linguistica e ciências sociais (1969), texto que exprime um posicionamento que, a princípio, intriga leitores acostumados, por exemplo, a associar Foucault e Análise do Discurso: "Não sou estruturalista [...] Quando falo de estruturalismo, falo dele como um objeto epistemológico que me é contemporâneo. Isso dito, há um método que me interessa em linguística [...] e que foi batizado com o nome de gramática gerativa ou transformacional" (FOUCAULT, 2000d, p. 177). Em que consistiria esse interesse de Foucault pelo Gerativismo? Não tratando tal excerto isoladamente, e considerando os diversos posicionamentos já explicitados, sabemos que Foucault nunca se propôs a fazer, por exemplo, análises sintáticas gerativas; no entanto, há uma característica do conceito de língua foucaultiano que toca 
alguns fundamentos do Gerativismo, conforme podemos observar no texto Sobre a arqueologia das ciências:

Uma língua [...] é um conjunto finito de regras que autoriza um número infinito de performances. O discurso, em contrapartida, é um conjunto sempre finito e atualmente limitado unicamente pelas sequências linguísticas que foram formuladas; elas podem ser certamente inumeráveis, podem, por sua massa, ultrapassar qualquer capacidade de registro, de memória ou de leitura: não obstante, elas constituem um conjunto finito. A questão que a análise da língua coloca, a respeito de um fato qualquer de discurso, é sempre: segundo que regras tal enunciado foi construído e, consequentemente, conforme que regras outros enunciados semelhantes poderiam ser construídos? A descrição do discurso coloca uma questão diferente: como ocorre que tal enunciado tenha surgido e não outro em seu lugar? (FOUCAULT, 2000f, p. 92)

A primeira asserção do excerto acima poderia ser eventualmente encontrada em um manual sobre o Gerativismo. Em que aspecto tal proposição concerne ao discurso? Pode-se desenvolver essa questão se considerarmos a língua, remontando à Arqueologia do Saber, como condição para a construção de enunciados. Se as regras de uma língua são finitas e suas performances infinitas, Foucault acrescenta que o discurso limita essa série de performances. Isso significa dizer que, a título de construção formal, uma regra produz séries infinitas, mas, a partir de dado posicionamento discursivo, não se pode dizer tudo e em qualquer lugar. Foucault deixa claro que o conjunto finito de enunciados permitidos por um discurso é dificilmente apreensível, fato que não denega o caráter de finitude. A partir do que um discurso "permite dizer", o linguista, com base foucaultiana, pode investigar o porquê das materialidades estarem dispostas de uma forma e não de outra, o porquê de silenciamentos, de retificações, de incursóes parafrásticas, de estratégias de legitimação da fala etc.

Com base nos trechos da obra de Michel Foucault que trouxemos para discussão, é possível esboçar algumas conclusóes acerca da relação entre as pesquisas com base foucaultiana na Linguística e certos conceitos considerados fundamentais no interior dessa disciplina. Não sendo propriamente um lin- 
guista e nunca se propondo como tal, podemos dizer que Foucault não tenta instrumentalizar um modelo de análise propriamente linguística. Focalizando o que chama de discurso, ele analisa as condiçóes de possibilidade dos sentidos. A necessidade da materialidade, nesse panorama, é uma das características do enunciado foucaultiano; ela não é mero suporte dos discursos, mas os constitui, sobretudo ao considerarmos a questão: "Por que apareceu um enunciado e não outro em seu lugar?”, questão que implica, por exemplo, a consideração de dadas relações associativas, de seleção, e sintagmáticas, de combinação. $\mathrm{O}$ linguista, ao basear algumas reflexóes de sua pesquisa na análise enunciativa proposta na Arqueologia, entretanto, é convocado a estabelecer relaçóes que o legitimem dentro desse campo de estudo. Por isso, em estudos linguísticos, outras relaçôes, não instrumentalizadas, mas suscitadas por Foucault, podem aparecer e aparecem. As oposiçôes entre os signos, constitutivas dos valores, para citarmos um exemplo, certamente sofrem um tratamento peculiar se o pesquisador olha para a mudança dos sentidos dos signos no interior das várias formações discursivas. O que, para uma formação discursiva, pode-se conceber como uma relação supostamente sinonímica, para outra pode produzir conotaçóes pejorativas ou indesejadas a depender da seleção dos signos, fato que modificaria as próprias relações de oposição que constituem o valor.

A interpretação maniqueísta relativa à oposição "sistema fechado" e questôes como sujeito, historicidade, enunciação, assim, perde coerência ao considerarmos que o próprio Saussure demonstrava náo recusar a possibilidade de estudos posteriores que expandiriam aspectos relativos ao objeto língua, como a enunciação, por exemplo: "Cada vez que emprego a palavra Senhores, eu lhe renovo a matéria; é um novo ato fônico e um novo ato psicológico" (SAUSSURE, 1972, p. 126). Concordamos com Milner (1989) quando ele explica que a distinção entre uma perspectiva teórica e outra não provém do simples fato de uma proposição ser falsa em uma perspectiva e verdadeira na "concorrente"; essa distinção é definida pelo fato de não podermos falar de uma mesma proposta para as duas perspectivas. $\mathrm{O}$ olhar para a língua, em uma abordagem foucaultiana, portanto, estabelece recortes e objetivos definidos, assim como seriam estabelecidos parâmetros de focalização em outras abordagens teóricas, quando trazidas para o interior da Linguística. 


\section{Referências}

COURTINE, Jean-Jacques. O discurso comunista endereçado aos cristãos. Trad. Cristina de Campos Velho Birck [et al.]. São Paulo: Edufscar, 2009.

DUCROT, Oswald. Estruturalismo e Linguística. São Paulo: Cultrix, 1968.

FOUCAULT, Michel. As palavras e as coisas. Trad. Salma Tannus Muchail. $8^{\mathrm{a}}$ ed. São Paulo: Martins Fontes, 1999.

FOUCAULT, Michel. Retornar à história. In: Ditos e Escritos II. Trad. Elisa Monteiro. Organização e seleção de textos Manoel Barros da Mota. Rio de Janeiro: Forense Universitária, 2000a.

. Linguagem e Literatura. In: MACHADO, Roberto. Foucault, a filosofia e a literatura. Rio de Janeiro: Jorge Zahar Ed., 2000b.

. Sobre as maneiras de escrever a história. In: Ditos e Escritos II. Tradução Elisa Monteiro. Organização e seleção de textos Manoel Barros da Mota. Rio de Janeiro: Forense Universitária, 2000c.

Linguística e ciências sociais. In: Ditos e Escritos II. Tradução Elisa Monteiro. Organização e seleção de textos Manoel Barros da Mota. Rio de Janeiro: Forense Universitária, 2000d.

- A Arqueologia do Saber. Trad.Luiz Felipe Baeta Neves. 6a ed. Rio de Janeiro: Forense Universitária, 2000e.

- Sobre a arqueologia das ciências. Resposta ao círculo de epistemologia. In: Ditos e Escritos II. Trad. Elisa Monteiro. Organização e seleção de textos Manoel Barros da Mota. Rio de Janeiro: Forense Universitária, $2000 \mathrm{f}$.

. Resposta a uma questão. In: Ditos e Escritos VI. Trad. Ana Lúcia Paranhos Pessoa. Organização e seleçáo de textos Manoel Barros da Mota. Rio de Janeiro: Forense Universitária, 2010.

MILNER, Jean-Claude. Introduction à une science du langage. Paris: Editions du Seuil, 1989.

SAUSSURE, Ferdinand de. Curso de Linguistica Geral. São Paulo: Cultrix, 1972. 


\title{
MICHEL FOUCAULT ET LES ETUDES LINGUISTIQUES: REFLECTIONS SUR LES NOTIONS DE LANGUE ET STRUCTURE DANS L'ANALYSE ARCHÉOLOGIQUE
}

\begin{abstract}
RÉSUMÉ
Cet article présente une refléxion sur l'insertion de l'œuvre de Michel Foucault dans les études linguistiques. Pour ce faire, nous nous concentrons sur le développement des notions de langue et de structure - importantes à ce domaine d'étude - dans certains textes de l'auteur, afin de souligner les convergences et les déplacements effectués.
\end{abstract}

MOTS-CLÉS: Foucault; langue; analyse archéologique.

Recebido 25/03/14

Aprovado 06/07/14 